\title{
The Performance of Stock Portfolios formed Using Fuzzy Logic
}

\author{
Andrew J. Jacob ${ }^{1}$, Amit K. Sinha ${ }^{2 *}$ \\ ${ }^{1}$ Information Analyst at Caterpillar \\ ${ }^{2}$ Bradley University, Email: asinha@fsmail.bradley.edu
}

\begin{abstract}
Expert systems, a type of artificial intelligence that replicate how experts think, can aide unskilled users in making decisions or apply an expert's thought process to a sample much larger than could be examined by a human expert. In this paper, an expert system that ranks financial securities using fuzzy membership functions is developed and applied to form portfolios. Our results indicate that this approach to form stock portfolios can result in superior returns than the market as measured by the return on the S\&P 500. These portfolios may also provide superior risk-adjusted returns when compared to the market.
\end{abstract}

Keywords: Expert Systems; Stock returns; portfolios; fuzzy logic; Sharpe ratio; Treynor ratio

JEL Classification: C8, G1, G11

\section{Introduction}

Expert System technology has seen its application in wide variety of disciplines including medical sciences, engineering, agriculture, and stock selection (Kamley, R S, and Jaloree 2015; Markic, Tomic, and Pavlovic 2009). The form of expert systems and artificial intelligence technology that has seen a wide application in finance is related to Fuzzy Logic (Chen et al. 2017; Cheung and Kaymak 2008; Chourmouziadis and Chatzoglou 2016; Korol 2014; Malagoli, Magni, and Mastroleo 2007; Nedović and Devedžić 2002; Nguyen 2016; Xidonas et al. 2009; Zhou and Dong 2004). These expert systems do a very good job of replicating how financial experts think, but when it comes to choosing the best investment opportunities, expert systems offer new opportunities and new ways to analyze not just one security, but all of the securities in a given universe. Furthermore, through use of fuzzy sets, all securities in a universe can be compared relative to each other and the best investment opportunities can be selected, given what investment opportunities are available. This manuscript contributes to the ever growing literature of the application of artificial intelligence, expert systems, and specifically, fuzzy logic to group US stocks into portfolios.

This manuscript differs from the other application of fuzzy logic to stock selection and portfolio formation in both methodological application and data use. It explores the application of fuzzy ranking and a holistic approach to ratio analysis. We develop composite fuzzy scores by estimating a weighted average using fuzzy values of twenty-two different variables. Standardized beta coefficients as discussed in (Bring 1994) are used for weighting purposes. The fuzzy values are used to form portfolios of stocks for the period between 1994 and 2014. Results indicate that at least one portfolio formed using our methodology provides superior risk-return performance when compared to the market portfolio.

Section 2 provides a brief literature review of overview the application of fuzzy logic in finance, while Section 3 has the methodology. Section 4 is the data section. Section 5 discusses the results while Section 6 has the conclusion.

\section{Literature Review}

Expert systems in general are well suited to deal with information such as financial ratios, indicators of performance for firms, and are able to draw conclusions in ways that are remarkably similar to the way humans think (Chen et al. 2017; Cheung and Kaymak 2008; Chourmouziadis and Chatzoglou 2016; Korol 2014; Malagoli et al. 2007;

\footnotetext{
Copyright (C) 2018 Andrew J. Jacob et al.

doi: 10.24294/fsj.v1i2.814

EnPress Publisher LLC.This work is licensed under the Creative Commons Attribution-NonCommercial 4.0 International License (CC BY-NC 4.0).

http://creativecommons.org/licenses/ by/4.0/
} 
Nedović and Devedžić 2002; Nguyen 2016; Xidonas et al. 2009; Zhou and Dong 2004). Fuzzy systems specifically have been tested and deemed safe and useful for applications in business and finance (Malagoli et al. 2007). 2007; Nedović and Devedžić 2002; Nguyen 2016; Xidonas et al. 2009; Zhou and Dong 2004). Fuzzy systems specifically have been tested and deemed safe and useful for applications in business and finance (Malagoli et al. 2007).

Our paper differs from (Chen et al. 2017; Nguyen 2016) as they both apply fuzzy logic algorithm to mean-variance-skewness-kurtosis framework while we mostly focus on using balance sheet, income statement, price ratios, and some market data like stock return, beta and trading volume. While (Chourmouziadis and Chatzoglou 2016; Xidonas et al. 2009) apply fuzzy trading system to daily data for stocks listed on the Athens Stock Exchange, we apply our methodology to the US stocks. (Korol 2014) applies a fuzzy logic approach to model and forecast exchange rates. While (Malagoli et al. 2007) apply the IF-Then fuzzy logic for rating and pricing firms, we form and evaluate performance of stock portfolios. Our paper also differs from (Nedović and Devedžić 2002) as they survey and discuss a number of expert systems commonly used in different areas of finance ${ }^{1}$ while we empirical apply our methodology. (Cheung and Kaymak 2008; Zhou and Dong 2004) apply fuzzy logic to technical analysis while our manuscript is focused on fundamental analysis and portfolio formation.

Our manuscript also uses a unique approach to obtain a composite fuzzy score. While financial data can be fuzzified by applying fuzzy logic, financial variables while important, may differ in their significance for consideration. Additionally, the relative importance of these variables could also change from year to year. To address this issue in an unbiased manner we apply standardized beta coefficient approach as discussed in (Bring 1994) to appropriately weight our fuzzy values and calculate a weighted average fuzzy score for all the stocks. Portfolios are formed by using these fuzzy scores.

\section{Methodology}

An important step in the fuzzification of financial data, is the identification of minimizing and maximizing factors. Minimizing factors are factors that have an inverse relationship with return, meaning that a factor is better in terms of return when it is smaller. Maximizing factors have a direct relationship with return and are better when maximized. Whether a factor should be minimized or maximized was determined by applying traditional fundamental valuation logic. For example, if a price to earnings ratio is low relative to companies in a universe, the company is considered to be undervalued. Therefore, the price to earnings would be a minimizing factor assuming a lower price to earnings ratio is preferable to a higher one.

The next step in the process is the identification of the largest and the smallest values of the variables in consideration. The smallest value of the minimizing variables is assigned a value of 1 , while the largest value is assigned a value of 0 . For the maximizing variables, the smallest variable gets a value of 0 , and the larges a value of 1 . A fuzzy value is estimated for each value in between the highest and lowest values of each variable using the following membership function:

$$
\begin{gathered}
f(x)=\left\{\begin{array}{c}
\frac{1}{\max -\min }(x)+b \text {, if maximizing factor } \\
\frac{1}{\min -\max }(x)+b \text {, if minimizing factor }
\end{array}\right. \\
\text { where } \\
\mathrm{b}=\left\{\begin{array}{l}
1-\frac{1}{\max -\min }(\max ), \text { if maximizing factor } \\
1-\frac{1}{\min -\max }(\min ), \text { if minimizing factor }
\end{array}\right.
\end{gathered}
$$

\footnotetext{
${ }^{1}$ For example, PORT-MAN is used in banking and management, INVEX is used in investment advisory, FAME in financial
} marketing, and DEVEX for currency exchange. 
After having obtained fuzzy values for all factors, multiple regressions were run on annual data to obtain the standardized beta coefficients. (Bring 1994) provides a good overview about the estimation of standardized beta coefficients. Consider the following equation with dependent variable $\mathrm{y}$, and several independent variables $\mathrm{x}_{\mathrm{i}}$. The usual assumptions regarding multiple regressions apply.

$$
\mathrm{y}=\alpha+\beta_{1} \mathrm{x}_{1}+\beta_{2} \mathrm{x}_{3}+\ldots+\beta_{\mathrm{k}} \mathrm{x}_{\mathrm{k}}+\varepsilon
$$

The typical interpretation of the coefficients of this equation, especially if the coefficients are significant, is that a change on 1 unit in $x_{i}$ changes y by $\beta_{i}$. This interpretation, however, does not provide any information about the relative importance of the explanatory variables. The approach to standardize regression coefficients, although not without controversy $^{2}$, allows the determination of the comparative magnitude of the independent variables in the regression model.

While (Bring 1994) discusses two approaches to estimating standardized variables, the process used in this manuscript is one where the standardized regression coefficient is obtained by dividing a parameter estimate by the ratio of the sample standard deviation of the dependent variable by that of the independent variable. Accordingly, the standardized parameter coefficients for parameter estimates in equation 2 are as below.

$$
\mathrm{B}_{\mathrm{i}}=\frac{\hat{\beta}_{\mathrm{i}}}{\left(\frac{\sigma_{\mathrm{y}}}{\sigma_{\mathrm{x}, \mathrm{i}}}\right)}=\hat{\beta}_{\mathrm{i}}\left(\sigma_{\mathrm{y}} / \sigma_{\mathrm{x}, \mathrm{i}}\right)
$$

The standardized parameter estimates obtained in equation 3 is converted to relative weights by using the following equation.

$$
\mathrm{w}_{\mathrm{i}}=\frac{\mathrm{abs}\left(\mathrm{B}_{\mathrm{i}}\right)}{\sum_{\mathrm{i}}^{\mathrm{n}} \mathrm{abs}\left(\mathrm{B}_{\mathrm{i}}\right)}
$$

The absolute value of each standardized coefficient is divided by the sum of the absolute value of all the standardized coefficients. This allows the coefficients to be converted into weights based on the relative significance of each independent variable. Using the weights from equation 5 and fuzzy values from application of equation 1, a weighted average fuzzy score is obtained for each stock using the following equation.

$$
\mathrm{FS}_{\mathrm{i}}=\sum \mathrm{w}_{\mathrm{i}} \mathrm{b}_{\mathrm{i}}
$$

This score is the security's fuzzy score relative to the other securities. As all factors are now on the same scale, they can be weighted and combined into a meaningful aggregate fuzzy score.

As an example of the implementation of our methodology, let's assume that the returns of the five firms in Table 1 Panel A are dependent on two variables: var1 and var2. The variable var1 is a maximizing variable while var2 is a minimizing variable. As var1 is a maximizing variable, its value of 8.05 for firm 2 is assigned to have a value of 1 , and its value of 2.56 for firm5, is assigned to have a value of 0 . As var2 is a minimizing variable, its lowest value and highest values are assigned values of 1 and 0 respectively. Fuzzy maximum and minimum variables are in Panel B of Table 1.The following fuzzy membership function applied.

where $b$ is estimated as

$$
f(x)= \begin{cases}\frac{1-0}{\max -\min }(x)+b, & \text { if maximizing factor } \\ \frac{1-0}{\min -\max }(x)+b, & \text { if minimizing factor }\end{cases}
$$

$$
b= \begin{cases}1-\frac{1}{\max -\min }(\max ), & \text { if maximizing factor } \\ 1-\frac{1}{\min -\max }(\min ), & \text { if minimizing factor }\end{cases}
$$

As var1 is a maximizing variable, its value of 8.05 for firm 2 is assigned to have a value of 1 , and its value of 2.56

\footnotetext{
${ }^{2}$ Some manuscripts raising objections to the use of standardized regression coefficients are(Achen 1982), (Darlington 1990), (Greenland, Schlesselman, and Crigui 1986), (Hanushe and Jackson 1977), (Kim and Ferree 1981), (King 1986), and (Pedhazur 1982).
} 
for firm5, is assigned to have a value of 0 . As var 2, is a minimizing variable, its lowest value and highest values are assigned values of 1 and 0 respectively.

Plugging values in Eq. 1a, we obtain values of $\mathrm{b}$ as show below:

$$
b=\left\{\begin{array}{cc}
1-\frac{1}{8.05-2.56}(8.05)=-0.4663 & \text { if maximizing factor } \\
1-\frac{1}{0.98-5.62}(0.98)=1.2112 & \text { if minimizing factor }
\end{array}\right.
$$

Appropriately applying values of $\mathrm{b}$ to values of var1 and var2 for all firms, fuzzy values are obtained. Panel $\mathrm{C}$ in Table 1 provides the fuzzy and crisp values both variables var1 and var 2.

The next in the process, requires running the following multiple regression equation shown below to get standardized beta coefficients. The regressions are carried out on the fuzzy values. Similar to variables var1 and var2, the return is fuzzified as well. The regression output is in Panel D of Table 1.

$$
\text { return }_{i}=a_{0}+b_{1} \operatorname{var}_{i}+b_{2} \operatorname{var}_{i}+\epsilon_{i}
$$

The relative weights of the standardized beta coefficients are estimated by using the equations below.

$$
\begin{aligned}
& w_{1}=v a r 1_{s b_{-} w}=\frac{a b s(0.8457)}{a b s(0.8457)+a b s(-1.1340)}=0.4272 \\
& w_{2}=v a r 2_{s b_{-} w}=\frac{a b s(-1.1340)}{a b s(0.8457)+a b s(-1.1340)}=0.5728
\end{aligned}
$$

The fuzzy score $\left(\mathrm{f}_{\mathrm{s}}\right)$ for each stock is estimated as the weighted average of the fuzzy values.

$$
f_{s}=w_{1} \operatorname{var} 1_{f}+w_{2} \operatorname{var} 2_{f}
$$

\begin{tabular}{|c|c|c|c|c|c|c|}
\hline \multicolumn{7}{|c|}{ Panel A: Crisp values of variables } \\
\hline & \multicolumn{6}{|l|}{ Variable } \\
\hline Firm & \multicolumn{2}{|l|}{ Return } & \multicolumn{2}{|l|}{ var1 } & \multicolumn{2}{|l|}{ var2 } \\
\hline Firm 1 & \multicolumn{2}{|l|}{$8.12 \%$} & \multicolumn{2}{|l|}{3.16} & \multicolumn{2}{|l|}{2.83} \\
\hline Firm 2 & \multicolumn{2}{|l|}{$7.01 \%$} & \multicolumn{2}{|l|}{8.05} & \multicolumn{2}{|l|}{5.62} \\
\hline Firm 3 & \multicolumn{2}{|l|}{$12.25 \%$} & \multicolumn{2}{|l|}{6.23} & \multicolumn{2}{|l|}{0.98} \\
\hline Firm 4 & \multicolumn{2}{|l|}{$8.21 \%$} & \multicolumn{2}{|l|}{2.98} & \multicolumn{2}{|l|}{1.92} \\
\hline Firm 5 & \multicolumn{2}{|l|}{$7.23 \%$} & \multicolumn{2}{|l|}{2.56} & \multicolumn{2}{|l|}{2.21} \\
\hline \multicolumn{7}{|c|}{ Panel B: Fuzzy values for the best and worst crisp (values } \\
\hline & \multicolumn{6}{|l|}{ Variables } \\
\hline Firm & var1 (Crisp) & \multicolumn{2}{|c|}{ var1 (Fuzzy) } & \multicolumn{2}{|l|}{$\operatorname{var2}($ Crisp) } & var2 (Fuzzy) \\
\hline Firm 1 & 3.16 & & & 2.83 & & \\
\hline Firm 2 & 8.05 & 1.00 & & 5.62 & & 0.00 \\
\hline Firm 3 & 6.23 & & & 0.98 & & 1.00 \\
\hline Firm 4 & 2.98 & & & 1.92 & & \\
\hline Firm 5 & 2.56 & 0.00 & & 2.21 & & \\
\hline \multicolumn{7}{|c|}{ Panel C: Crisp and Fuzzy values } \\
\hline & \multicolumn{6}{|l|}{ Variables } \\
\hline Firm & var1 (Crisp) & \multicolumn{2}{|c|}{$\operatorname{var1}\left(\right.$ Fuzzy) $\operatorname{var} 1_{f}$} & \multicolumn{2}{|l|}{$\operatorname{var} 2$ (Crisp) } & $\operatorname{var} 2\left(\right.$ Fuzzy) var $2_{\mathrm{f}}$ \\
\hline Firm 1 & 3.16 & \multicolumn{2}{|l|}{0.1093} & \multicolumn{2}{|l|}{2.83} & 0.6013 \\
\hline Firm 2 & 8.05 & \multicolumn{2}{|l|}{1.0000} & \multicolumn{2}{|l|}{5.62} & 0.0000 \\
\hline Firm 3 & 6.23 & \multicolumn{2}{|l|}{0.6685} & \multicolumn{2}{|l|}{0.98} & 1.0000 \\
\hline Firm 4 & 2.98 & 0.0765 & & 1.92 & & 0.7974 \\
\hline
\end{tabular}

After fuzzy scores for all the variables are estimated, the $50^{\text {th }}$ percentile value for the fuzzy score is used to group stocks into two portfolios. Portfolio 1 is made up of stocks below the $50^{\text {th }}$ percentile value, and portfolio 2 is made up of stocks above the $50^{\text {th }}$ percentile value. Panel E in Table 1 presents the fuzzy score, $50^{\text {th }}$ percentile and portfolios. 


\begin{tabular}{|c|c|c|c|c|c|c|c|}
\hline \multicolumn{2}{|l|}{ Firm 5} & \multicolumn{2}{|l|}{2.56} & 0.0000 & 2.21 & \multicolumn{2}{|c|}{0.7349} \\
\hline \multicolumn{8}{|c|}{ Panel D: Parameter Estimates } \\
\hline Variable & Coefs & t-stat & p-value & Standardized betas & R-sq & Adj Rsq & F-value \\
\hline Intercept & 0.0887 & 11.73 & 0.0072 & 0.0000 & & & \\
\hline var1 & 0.0074 & 4.340 & 0.0492 & 0.8457 & $94.70 \%$ & $89.40 \%$ & 17.86 \\
\hline var2 & -0.0137 & -5.820 & 0.0283 & -1.1340 & & & \\
\hline
\end{tabular}

Panel E: Portfolio based on fuzzy score

\begin{tabular}{l|l|l|l}
\hline Firm & Fuzzy Score & $\mathbf{5 0}^{\text {th }}$ percentile & Portfolio \\
\hline Firm1 & 0.3911 & 0.4272 & 1 \\
\hline Firm2 & 0.4272 & 0.4272 & 1 \\
\hline Firm3 & 0.8584 & 0.4272 & 2 \\
\hline Firm4 & 0.4894 & 0.4272 & 2 \\
\hline Firm5 & 0.4210 & 0.4272 & 1 \\
\hline
\end{tabular}

Table 1. Example

\section{Data}

The relevance and the economic significance of the methodology is tested by applying it to data extracted from Thompson Reuter's DataStream ${ }^{3}$. Data was initial extracted at an annual frequency for the period between 1973 and 2014. The financial variables extracted from DataStream are common equity (ce), common shares outstanding (cso), dividend per share (dps), earnings per share (eps), fixed assets (fa), market value (mv), net profit (netp), net working capital (nwc), quick ratio (qr), operating profit margin, stock price (prca), sales, total assets (ta), total capital (tcap), total debt (td), and trading volume (vol). To avoid results to be unduly affected by low prices, we only consider stocks that have a price of at least five dollars. Firms with zero or negative equity were excluded from consideration. So were stocks with negative sales. Besides, to minimize the impact of extreme values, variables are windsorizedat the $0.5 \%$ and the $99.5 \%$ levels, i.e., values less than the $0.5 \%$ percentile and greater than the $99.5 \%$ percentile are replaced by the $0.5 \%$ and $99.5 \%$ values. The data was windsorized every year, before the stocks were grouped into portfolios.

Using these extracted variables, the following variables were estimated: self-financing ratio (sfr), financial leverage (fl), capital employed ratio (cer), overall solvency ratio (os), price to sales ratio (ps), total asset turnover ratio (tatr), Tobin's q (tq), payout ratio (pout), price earnings ratio (pe), book to price ratio (bp), profit margin (pm), price to dividend ratio (pdps), sales growth rate (s_g) and dividend growth rate (dps_g). These variables were estimated by using the formulae shown below.

$$
\begin{aligned}
& s f r=\frac{c \mathrm{e}}{t c a p} ; f l=\frac{t d}{c e} ; c e r=\frac{(f a+n w c)}{t c a p} ; o s=\frac{t a}{t d} ; \\
& p s=\frac{p r c a}{(\text { sales } / \text { prca })} ; t a t r=\frac{\text { sales }}{t a} ; e m=\frac{t a}{c e} ; t q=\frac{(m v+t d)}{t a} ; \\
& \text { pout }=\frac{d p s}{\text { eps }} ; p e=\frac{p r c a}{\text { eps }} b p=\frac{(c e / c s o)}{p r c a} ; p m=\frac{\text { netp }}{\text { sales }} ; \\
& p d p s=\frac{p r c a}{d p s} ; s_{-} g=\ln \left(\frac{\text { sales }_{t}}{\text { sales }_{t-1}}\right) ; d p s_{-} g=\ln \left(\frac{d p s_{t}}{s d p s_{t-1}}\right)
\end{aligned}
$$

The S\&P 500 index values were also extracted from DataStream while the 3-month T-bill rates were obtained from the website of Federal Reserve Bank of St. Louis. Annual market returns were estimated by taking the natural log of consecutive S\&P values. Similarly, stock returns were estimated be taking the natural log of prices from consecutive years.

${ }^{3}$ The data was for stocks in DataStream seven constituted research lists. These lists include data for stocks that actively traded as well as for those stocks that are not. 


$$
\text { sktret }_{i, t}=\ln \left(\frac{\text { prca }_{i, t}}{\text { prca }_{i, t-1}}\right) ; \text { mktret }_{t}=\ln \left(\frac{S \& P 500_{t}}{S \& P 500_{t-1}}\right)
$$

Stock beta were estimated using rolling 20-year rolling window of individual stock returns and return on the S\&P 500. Beta is estimated only for those stocks that have at least ten years of return data points during the twenty-year window. The traditional covariance formulae shown in the equation below was used to estimate stock beta. After the beta was calculated, any stock with negative values for beta were eliminated for further consideration during year the year the stock had a negative beta.

$$
\beta_{i}=\frac{\operatorname{Cov}\left(r_{i}, R_{M}\right)}{\sigma_{M}^{2}}=\frac{\sum_{i=1}^{n}\left(r_{i}-\overline{r_{i}}\right)\left(R_{M}-\overline{R_{M}}\right)}{\sum_{i=1}^{n}\left(R_{M}-\overline{R_{M}}\right)^{2}}
$$

The variables considered to maximizing variables are: stock return, stock beta, quick ratio, operating profit margin, self-financing ratio, capital employed, overall solvency ratio, price to sales ratio, total asset turnover ratio, Tobin's q, profit margin, price to dividend per share ratio, lagged stock return, trading volume, sales growth rate, and dividend growth rate. The variables considered to be minimizing variables are: book to price ratio, payout ratio, financial leverage ratio, price to earnings ratio, and market value. The choice of variables defined as maximizing or minimizing is based on the assumption whether these variables are going to have positive or negative impact on stock returns. Table 2 tabulates the variables and their perceived impact on stock performance. A maximizing variable increases return, while a minimizing variable has a negative impact on stock returns. While effort has been made to use existing finance literature as a guide to decide whether variables are maximizing or minimizing, classification of variables into maximizing or minimizing could be arbitrary.

\begin{tabular}{l|l}
\hline Variables & Direction \\
\hline Book to Price Ratio & Maximizing \\
\hline Capital employed Ratio & Maximizing \\
\hline Dividend growth rate & Maximizing \\
\hline Financial Leverage & Minimizing \\
\hline Market Value & Minimizing \\
\hline Operating Profit Margin & Maximizing \\
\hline Overall Solvency Ratio & Maximizing \\
\hline Payout Ratio & Maximizing \\
\hline Price to Dividend per share & Minimizing \\
\hline Price to Earnings Ratio & Minimizing \\
\hline Profit Margin & Maximizing \\
\hline Price to Sales & Minimizing \\
\hline Quick Ratio & Maximizing \\
\hline Sales growth rate & Maximizing \\
\hline Self-Financing Ratio & Maximizing \\
\hline Size & Minimizing \\
\hline Stock Return and Lagged Stock Return & Maximizing \\
\hline Stock Beta & Maximizing \\
\hline Lagged Stock Return & Maximizing \\
\hline Tobin's Q & Maximizing \\
\hline Total Assets Turnover ratio & Maximizing \\
\hline Volume & Maximizing \\
\hline
\end{tabular}

Table 2. Variable Direction

This table shows the variables used in the manuscript. It also tabulates the direction of the impact of the variable. A 
maximizing variables is considered to have increase future returns, while minimizing variables are considered to decrease future returns. Based on the direction of the future impact, the raw values of the variables are converted into fuzzified variables using the following equation:

$$
f(x)=\left\{\begin{array}{ll}
\frac{1-0}{\max -\min }(x)+b, & \text { if maximizing factor } \\
\frac{1-0}{\min -\max }(x)+b, & \text { if minimizing factor }
\end{array} ;\right.
$$

where

$$
b= \begin{cases}1-\frac{1}{\max -\min }(\max ), & \text { if maximizing factor } \\ 1-\frac{1}{\min -\max }(\min ), & \text { if minimizing factor }\end{cases}
$$

Our methodology to apply fuzzy logic requires variables considered to be classified into maximizing and minimizing variables. We selected stock beta to be a maximizing variable, as it measures systematic risk. Empirical tests (Kandel and Stambaugh 1987, 1989, 1995; Lintner 1965a; Miller and Scholes 1972; Roll 1977; Roll and Ross 1994) of the risk-return relationship as hypothesized by the Capital Asset Pricing Model (Lintner 1965b; Mossin 1966; Sharpe 1964) show that risk premia will be proportional to exposure to systematic risk (Bodie, Kane, and Marcus 2018).

We consider quick ratio to be a maximizing variable, as a higher quick ratio indicates a better ability of the firm to meets its liquidity needs. Like current ratio, quick ratio measures a firm's ability to bills using its most liquid assets (Bodie et al. 2018), but is often preferred to current ratio(Reilly and Brown 2009). We consider the total asset turnover ratio as a maximizing variable because as per (Bodie et al. 2018), it indicates efficiency of use of a firm's asset to generate sales. We consider Tobin's $Q$ to be a maximizing variables as firms that have Tobin's $Q$ value greater than one have greater incentive, which should result in higher returns to shareholders (Brainard and Tobin 1968; Lindenberg and Ross 1981; Tobin 1969).

As higher profit margin $(\mathrm{pm})$ boosts potential for growth using less external funds (Brigham and Daves 2013) we consider profit margin as a maximizing variable. We also consider operating profit margin a maximizing variable, as it relates a firm's performance to its operations (Brigham and Daves 2013) and accordingly, a higher number is more desirable than a lower number. We consider the payout ratio (pout) to be a minimizing variables, because a lower and steady payout policy invariably lowers the cost of equity thereby maximizing stock price (Brigham and Daves 2013).

We consider self-financing ratio and overall solvency as maximizing variables, while we consider financial leverage to be a minimizing variable. A higher value of the self-financing ratio means more equity in total capital, thereby allowing the firm to invest in riskier projects without having to access the external capital markets. High equity also indicates a higher capacity for accessing the debt market and increase leverage. (Reilly and Brown 2009) point out that high levels of debt increase bankruptcy costs, and accordingly extremely high amounts of debt in the capital structure would be detrimental to the interest of increasing returns to shareholders. Accordingly, financial leverage is a minimizing variable in this study. As higher overall solvency ratio indicates more equity in the capital structure, and like the self-financing ratio, it is considered to be a maximizing variable. The capital employed ratio is considered to be a maximizing variable, as it shows the fraction of the total capital deployed in productive assets.

Price earnings, and price to sales ratios are considered to be minimizing variables. As (Bodie et al. 2018) point out risker firms have lower $\mathrm{P} / \mathrm{E}$ ratio, a low value for this ratio is indication for higher returns in the future for such stocks. Higher $\mathrm{P} / \mathrm{E}$ ratios, on the other hand are indication for lower future returns. A similar logic is used to consider price to sales ratio as a minimizing variable, and this variable is especially relevant if a firm has a negative net income. The book to price ratio is considered as a maximizing variables as it is found to be positively correlated with subsequent stock returns (Fama and French 1992; Penman, Richardson, and Tuna 2007).

We consider volume to be a maximizing variables primarily from the findings of (Chordia and Swaminathan 2000), who find that returns of higher trading volume stocks lead those with lower trading volume. The rationale for using lagged returns as maximizing variables comes from findings of (Jegadeesh and Titman 1993, 2001) who show 
that buying stocks with past positive returns lead to higher returns in the future.

Our motivation for considering size as a minimizing variable arises from the findings of (Fama and French 1992) who find that the coefficient of size to have a negative coefficient, thereby implying large size to provide lower returns. We consider the growth rate in sales to be a maximizing variable, because everything else the same, an increase in sales would improve a firm's bottom line, optimism about the future, higher profits, cash flows and returns to shareholders. As an increase in dividends exhibit managerial confidence about future prospects about of the firm, the dividend growth rate is considered a maximizing variable.

This methodology of portfolio formation would nevertheless be implementable. Raw variables are converted into fuzzy values using a membership function shown below. This function is similar to one shown in Equation 1.

$$
f\left(\operatorname{var}_{i}\right)= \begin{cases}\frac{1-0}{\max \left(\operatorname{var}_{i}\right)-\min \left(\operatorname{var}_{i}\right)}\left(\text { var }_{i}\right)+b, & \text { if maximizing factor } \\ \frac{1-0}{\min \left(\operatorname{var}_{i}\right)-\max \left(\operatorname{var}_{i}\right)}\left(\text { var }_{i}\right)+b, & \text { if minimizing factor }\end{cases}
$$

where $b$ is estimated as

$$
b= \begin{cases}1-\frac{1}{\max \left(\operatorname{var}_{i}\right)-\min \left(\operatorname{var}_{i}\right)}\left(\operatorname{var}_{i}\right), & \text { if maximizing factor } \\ 1-\frac{1}{\min \left(\operatorname{var}_{i}\right)-\max \left(\operatorname{var}_{i}\right)}\left(\operatorname{var}_{i}\right), & \text { if minimizing factor }\end{cases}
$$

The standardized beta coefficients are estimated by running the following multiple regression.

$$
\begin{gathered}
r e t_{i, t, f}=a_{i, t}+\operatorname{beta}_{i, t, f}+q r_{i, t, f}+o p m_{i, t, f}+s f r_{i, t, f}+c e r_{i, t, f}+o s_{i, t, f}+p s_{i, t, f}+t a t r_{i, t, f}+t q_{i, t, f}+p e_{i, t, f}+ \\
p m_{i, t, f}+p d p s_{i, t, f}+\operatorname{lag}_{-} r e t_{i, t, f}+\operatorname{vol}_{i, t, f}+s_{-} g_{i, t, f}+d p s_{-} g_{i, t, f}+b p_{i, t, f}+p o u t_{i, t, f}+f l_{i, t, f}+m v_{i, t, f}+\epsilon_{i, t}(7)
\end{gathered}
$$

The letter $\mathrm{f}$ in the subscript is indicate that the multiple regression was carried out using fuzzy values. These regressions are run every year and the standardized beta coefficients discussed in (Bring 1994) are extracted. Using the standardized coefficients, the relative weights of each variable is estimated by using the following equation which is similar to Eq. (4).

$$
w_{i}=\frac{a b s\left(\text { std_coeff_var }{ }_{i}\right)}{\left.\sum_{i=1}^{i=20} \text { abs(std_coeff_var }\right)}
$$

Using the fuzzy values from the membership functions in Eq. (6) and the weights of the standardized coefficients in Eq. (8), the composited fuzzy scores are obtained by using the equation below. This equation is similar to Eq. 5 .

$$
\text { fuzz_score }_{i}=\sum\left(w_{i}\right)\left(f\left(\text { var }_{i}\right)\right)
$$

Eq. (9) results in each stock having a unique fuzzy score. These scores are then sorted quintiles. The quintiles numbers are then used to group the stocks into five different portfolios: P1, P2, P3, P4 and P5, which are held for one year. At the end of the year the return on the five portfolios are calculated. A portfolio strategy, hereby referred to as the net portfolio, which involved shorting Portfolio P1 and taking a long position in portfolio P5 was also implemented. The entire methodology is repeated and portfolios rebalanced each year for the years between 1994 and 2014.

Table 3 presents the average return for each of these five portfolios, the risk-free return and the return on the market as measured by the return on the S\&P 500 for the period between 1994 and 2014. The performance of the portfolios are measured by the Sharpe ratio and the Treynor ratio, which are also presented in Table 3. These ratios are estimated using the formulae in Eq. 10a and $10 \mathrm{~b}$ respectively.

$$
\begin{aligned}
& \text { Share Ratio }{ }_{p, t}=\left(\frac{R_{p, t}-R f_{t}}{\sigma_{p}}\right) * 100 \\
& \text { Treynor Ratio } \text { R }_{p, t}=\left(\frac{R_{p, t}-R f_{t}}{\beta_{p, t}}\right) * 100
\end{aligned}
$$

The beta of the market is taken to 1 , while the beta of the portfolios is the average of the betas of the stocks in a portfolio. The annual betas of the portfolios are then averaged to obtain the portfolio betas for each portfolio between 1994 and 2014. The beta for the net portfolio is the difference between the betas of portfolios P1 and P5. The standard deviation of the portfolio is estimated using the returns of the portfolios. Table 3 also contains the performance of a portfolio strategy that involves shorting portfolio 1 and taking a long position in portfolio 5 .

The average returns of the portfolios range from $-0.28 \%$ for portfolio 1 to $10.46 \%$ for portfolio 5 . During this 
period the average risk-free return was $2.69 \%$ and the average annual return on the market was $7.07 \%$, while the net portfolio had an average return of 10.75\% over the 21 years, between 1994 and 2014. While the average return on the market is higher than portfolios 1, 2, 3, and 4, it is 3.39\% lower than that of portfolio 5, and 3.68\% lower than the net portfolio. While the Sharpe ratios for P5 and net portfolio is higher than that of the market, the Sharpe ratio of the market is higher than those of P1, P2, P 3, and P4. For the Treynor ratio, except for P1, all the other portfolios outperform the market on a risk-adjusted basis.

Table 4 provides the annual portfolio returns for each of the years in consideration. We can observe that the highest return on the market was $29.35 \%$ in 1995 while the worst at $-48.59 \%$ was in 2008 . While the worst performances of all five portfolios are lower than negative sixty-five percent, the worst performance for the net portfolio is $-48.91 \%$. The best performances for all five portfolios were above $35 \%$, with the highest being $76.40 \%$ for portfolio 5 in year 2000 , and $84.30 \%$ for the net portfolio also in year 2000. During this period the risk-free rate ranged from a minimum of $0.03 \%$ in 2014 to a high of $5.82 \%$ in 2000 . While a clear dominance of any of the portfolio over the market is not observed, the market also does not dominate all five portfolios between 1994 and 2014.

\begin{tabular}{l|l|l|l}
\hline Portfolio & Average Return & Sharpe Ratio & Treynor Ratio \\
\hline P1 & $-0.28 \%$ & -11.78 & -27.77 \\
\hline P2 & $3.91 \%$ & 4.55 & 5.39 \\
\hline P3 & $4.59 \%$ & 5.93 & 7.98 \\
\hline P4 & $4.07 \%$ & 4.39 & 4.75 \\
\hline P5 & $10.46 \%$ & 23.71 & 15.76 \\
\hline M5 - P1) & $10.75 \%$ & 27.47 & 20.86 \\
\hline Risk-Free & $7.07 \%$ & 22.64 & 4.38 \\
\hline
\end{tabular}

Table 3. Portfolio performance

\begin{tabular}{|c|c|c|c|c|c|c|c|c|}
\hline Year & P1 & P2 & P3 & P4 & P5 & (P5 - P1) & Market & $\mathbf{R f}$ \\
\hline 1994 & $-3.66 \%$ & $-1.76 \%$ & $-0.51 \%$ & $-1.96 \%$ & $-3.12 \%$ & $0.54 \%$ & $-1.55 \%$ & $4.25 \%$ \\
\hline 1995 & $19.46 \%$ & $25.26 \%$ & $22.25 \%$ & $19.04 \%$ & $27.11 \%$ & $7.65 \%$ & $29.35 \%$ & $5.49 \%$ \\
\hline 1996 & $11.04 \%$ & $11.67 \%$ & $17.33 \%$ & $14.60 \%$ & $18.83 \%$ & $7.79 \%$ & $18.45 \%$ & $5.01 \%$ \\
\hline 1997 & $20.14 \%$ & $18.81 \%$ & $16.87 \%$ & $17.00 \%$ & $16.04 \%$ & $-4.10 \%$ & $27.01 \%$ & $5.06 \%$ \\
\hline 1998 & $-11.11 \%$ & $-2.46 \%$ & $-10.60 \%$ & $-12.36 \%$ & $-19.17 \%$ & $-8.07 \%$ & $23.64 \%$ & $4.78 \%$ \\
\hline 1999 & $1.04 \%$ & $0.85 \%$ & $6.71 \%$ & $6.10 \%$ & $19.84 \%$ & $18.80 \%$ & $17.84 \%$ & $4.64 \%$ \\
\hline 2000 & $-7.62 \%$ & $28.79 \%$ & $56.24 \%$ & $51.72 \%$ & $76.40 \%$ & $84.03 \%$ & $-10.69 \%$ & $5.82 \%$ \\
\hline 2001 & $-43.50 \%$ & $-66.41 \%$ & $-75.10 \%$ & $-45.34 \%$ & $32.44 \%$ & $75.93 \%$ & $-13.98 \%$ & $3.39 \%$ \\
\hline 2002 & $-23.69 \%$ & $-0.81 \%$ & $11.05 \%$ & $18.03 \%$ & $28.23 \%$ & $51.92 \%$ & $-26.61 \%$ & $1.60 \%$ \\
\hline 2003 & $3.33 \%$ & $0.35 \%$ & $-17.04 \%$ & $-31.84 \%$ & $-45.58 \%$ & $-48.91 \%$ & $23.41 \%$ & $1.01 \%$ \\
\hline 2004 & $33.81 \%$ & $43.26 \%$ & $46.42 \%$ & $43.59 \%$ & $38.44 \%$ & $4.63 \%$ & $8.61 \%$ & $1.37 \%$ \\
\hline 2005 & $13.46 \%$ & $20.28 \%$ & $14.60 \%$ & $14.84 \%$ & $20.88 \%$ & $7.43 \%$ & $2.96 \%$ & $3.15 \%$ \\
\hline 2006 & $7.48 \%$ & $3.64 \%$ & $2.75 \%$ & $1.47 \%$ & $5.38 \%$ & $-2.10 \%$ & $12.77 \%$ & $4.73 \%$ \\
\hline 2007 & $14.78 \%$ & $13.12 \%$ & $12.67 \%$ & $10.02 \%$ & $12.17 \%$ & $-2.61 \%$ & $3.47 \%$ & $4.35 \%$ \\
\hline 2008 & $1.44 \%$ & $-4.59 \%$ & $-9.22 \%$ & $-9.58 \%$ & $-7.86 \%$ & $-9.30 \%$ & $-48.59 \%$ & $1.37 \%$ \\
\hline 2009 & $-74.36 \%$ & $-61.25 \%$ & $-65.21 \%$ & $-76.56 \%$ & $-68.26 \%$ & $6.10 \%$ & $21.07 \%$ & $0.15 \%$ \\
\hline 2010 & $35.27 \%$ & $34.89 \%$ & $53.58 \%$ & $63.29 \%$ & $65.76 \%$ & $30.49 \%$ & $12.03 \%$ & $0.14 \%$ \\
\hline 2011 & $-21.59 \%$ & $-13.83 \%$ & $-13.80 \%$ & $-18.17 \%$ & $-19.87 \%$ & $1.72 \%$ & $0.00 \%$ & $0.05 \%$ \\
\hline
\end{tabular}




\begin{tabular}{l|l|l|l|l|l|l|l|l}
\hline 2012 & $4.82 \%$ & $12.07 \%$ & $9.06 \%$ & $7.49 \%$ & $5.65 \%$ & $0.84 \%$ & $12.58 \%$ & $0.09 \%$ \\
\hline 2013 & $18.02 \%$ & $22.47 \%$ & $23.53 \%$ & $20.32 \%$ & $18.56 \%$ & $0.54 \%$ & $25.93 \%$ & $0.06 \%$ \\
\hline 2014 & $-4.51 \%$ & $-2.23 \%$ & $-5.08 \%$ & $-6.10 \%$ & $-2.11 \%$ & $2.40 \%$ & $10.79 \%$ & $0.03 \%$ \\
\hline Mean & $-0.28 \%$ & $3.91 \%$ & $4.59 \%$ & $4.07 \%$ & $10.46 \%$ & $10.75 \%$ & $7.07 \%$ & $2.69 \%$ \\
\hline
\end{tabular}

Table 4. Annual portfolio returns

This table provides the average annual returns of all the portfolios for each of the years in the study. Portfolios are formed based by grouping stocks into five portfolios (Port 1, 2, 3, 4 and 5) based on their fuzzy scores. The portfolios are rebalanced every year. The market return (Market) and the risk-free returns are also provided. Only those stocks with prices above $\$ 5$ were considered.

\section{Conclusion}

Stock picking is a tedious exercise requiring consideration of numerous pieces of information, especially if decisions made are to be objective and rational. Asset pricing models like CAPM and those proposed in (Fama and French 1992, 1993) among others may serve as frameworks to stock selection with only a few variables considered. However, a growing body of work including that by (Welch and Goyal 2008) use an exhaustive list of variables. Our manuscript provides an approach to decision making regarding stock selection and portfolio formation by using fuzzy logic to simplify decision making while considering an exhaustive list, twenty-two financial market and fundamental variables. This approach allows consideration of information contained in different financial ratios and variables, and by appropriately weighting that information, the final decision is based on only one composite fuzzy score. Accordingly, this approach represents the best of both worlds as its imultaneously allows for consideration of numerous variables, and simplify decision making.

In this paper we use fuzzy membership functions to convert raw values into fuzzy values. We weight the fuzzy values using a and standardized regression coefficients to estimated weighted average fuzzy scores. The fuzzy scores are then used to divide stocks into quintile portfolios, P1, P2, P3, P4, and P5. We also have one portfolio strategy where we short stocks We apply this strategy for 21 years between 1994 and 2014. Portfolios are balanced every year and held for one year. We also have one portfolio strategy, the net portfolio, where we short P1 and take a long position in P5.

Our results show the average return of one of the portfolios, P5, is higher than the other four portfolios and that of the market P5 outperforms the market by 3.39\% while a portfolio strategy of shorting P1 and taking a long position in P5 would have resulted in a rate of return $3.68 \%$ higher than that of the market. The risk-adjusted performance compares favorably for four of the five portfolios and the net portfolio when performance is measure by the Treynor ratio. When the Sharpe ratio is considered, P5 and the net portfolio outperforms the market on a risk-adjusted basis. These results indicated that the process of forming portfolios using a process that considers fuzzy logic could result in portfolios that outperform the market in average returns, as well as on a risk-adjusted basis.

\section{References}

1. Achen Christopher H. Interpreting and Using Regression. edited by J. L. Sullivan and R. G. Niemi. Newbury, CA: Sage Publications, 1982.

2. Attaran Mohsen. The coming age of fuzzy logic in manufacturing and services. Journal of Systems Management 1996; 47(2):4-12.

3. Bodie Zvi, Alex Kane, Alan Marcus. 2018. Investments. 11th ed. New York, NY: McGraw Hill Education.

4. Brainard William, James. Tobin. 1968. Pitfalls in financial model building. The American Economic Review 1968; 58(2):99-122. Retrieved from: http://www.jstor.org/stable/1831802.

5. Brigham Eugene F, Phillip R Daves. Intermediate Financial Management. 11th ed. South-Western Cengage Learning, 2013.

6. Johan B. 1994. How to standardize regression coefficients. The American Statistician 1994; 48(3):209. Retrieved from:http://www.jstor.org/stable/2684719?origin=crossref.

7. Chen Wei, Wang Y, Zhang J, et al. Uncertain portfolio selection with high-order moments. Journal of Intelligent; Fuzzy Systems 2017; 33(3):1397-1411.Retrieved from: http://www.medra.org/servlet/aliasResolver?alias=iospress\&amp;doi=10.3233/JIFS-17369. 
8. Cheung Wee Mien, Kaymak U. A fuzzy logic based trading system. Econometrics Journal of Rotterdam, 2008.

9. Chordia Tarun, Bhaskaran Swaminathan. Trading volume and cross-autocorrelations in stock returns. The Journal of Finance 2000; 55(2): 913-35. Retrieved from: http://doi.wiley.com/10.1111/0022-1082.00231.

10. Chourmouziadis Konstandinos, Prodromos D. Chatzoglou. An intelligent short term stock trading fuzzy system for assisting investors in portfolio management. Expert Systems with Applications 2016; 43: 298-311. Retrieved from: http://linkinghub.elsevier.com/retrieve/pii/S0957417415005230.

11. Darlington RB. Regression and linear models. McGraw-Hill: New York, 1990.

12. Fama EF, French KR. Cross-section of expected stock returns. Journal of Finance 1992; 47(2): 427-65. Retrieved from: http://onlinelibrary.wiley.com/doi/10.1111/j.1540-6261.1992.tb04398.x/full.

13. Fama EF, French KR. Common risk factors in the returns on stocks and bonds. Journal of Financial Economics 1993; 33(1): 3-56. Retrieved from: http://linkinghub.elsevier.com/retrieve/pii/0304405X93900235.

14. Greenland S, Schlesselman JJ, Crigui MH. The fallacy of employing standardized regression coefficients and correlations as measure of effect. American Journal of Epidemiology 1986; 123(2):203-8. Retrieved from: https://academic.oup.com/aje/article/57724/THE.

15. Hanushe EA, Jackson JE. Statistical Methods for Social Scientists. New York, NY: Academic Press, 1977.

16. Jegadeesh N, Titman S. Profitability of momentum strategies: An evaluation of alternative explanations. The Journal of Finance 2001; 56(2): 699-720. Retrieved from: http://dx.doi.org/10.1111/0022-1082.00342).

17. Jegadeesh N, Sheridan T. Returns to buying winners and selling losers: Implications for stock market efficiency. The Journal of Finance 1993; 48(1): 65-91.

18. Kamley S, Thakur RS, Shailesh J. 2015. Rule based approach for stock selection: An expert system. International Journal of Computing Algorithm 2015; 4(1): 15-18. Retrieved from: http://ijcoa.com/abstract_temp.php?id=V4-I1-P3.

19. Kandel S, Stambaugh RF. On correlations and inferences about mean-variance efficiency. Journal of Financial Economics 1987; 18(1): 61-90.

20. Kandel S, Stambaugh RF. Portfolio inefficiency and the cross-section of expected returns. The Journal of Finance 1995; 50(1): 157. Retrieved from: http://www.jstor.org/stable/2329242).

21. Kandel S, Stambaugh RF. A mean-variance framework for tests of asset pricing models. Review of Financial Studies 1989; 2(2): 125-56. Retrieved from: http://www.jstor.org/stable/2962045.

22. Kasabov NK. Foundations of neural networks, fuzzy systems, and knowlege engineering. Cambridge, MA: MIT Press, 1996.

23. Kim Jae on, Ferree GD. Standardization in causal analysis. Sociological Methods \&amp; Research 1981; 10(2): 187-210.

24. King G. 1986. How not to lie with statistics: Avoiding common mistakes in quantitative political science. American Journal of Political Science 1986; 30(3): 666. Retrieved from: http://www.jstor.org/stable/2111095?origin=crossref.

25. Korol T. A Fuzzy Logic Model for Forecasting Exchange Rates. Knowledge-Based Systems 2014; 67: 49-60. Retrieved from: http://linkinghub.elsevier.com/retrieve/pii/S0950705114002305.

26. Lindenberg EB, Ross SA. Tobin's Q ratio and industrial organization. Journal of Business 1981; 54(1):1-32. Retrieved from: http://www.jstor.org/stable/2352631.

27. Lintner J. Security prices, risk, and maximal gains from diversification. The Journal of Finance 1965a; $20(4): 587$. Retrieved from: http://www.jstor.org/stable/2977249?origin=crossref.

28. Lintner J. The valuation of risk assets and the selection of risky investments in stock portfolios and capital budgets. The Review of Economics and Statistics 1965b; 47(1): 13. Retrieved from: http://www.jstor.org/stable/1924119.

29. Malagoli S, Magni CA, Giovanni M. The use of fuzzy logic and expert systems for rating and pricing firms edited by C. A. Magni. Managerial Finance 2007; 33(11): 836-52. Retrieved from: http://www.emeraldinsight.com/doi/10.1108/03074350710823818.

30. Markic Brano, Dražena Tomic, Ivan Pavlovic. An expert system approach in stock selection attractive for investment. 2009; 297-300 in 13th International Research/Expert Confrence Trends in the Developement of Machinery and Associate Technology. Hammamet, Tunisia.

31. Miller MH, Myron S. Rate of return in relation to risk: A reexamination of some recent findings. in Studies in the Theory of Capital markets, edited by M. Jensen. New York, NY: Praeger, 1972.

32. Mossin Jan. Equilibrium in a capital asset market. Econometrica 1966; 34(4): 768. Retrieved from: http://www.jstor.org/stable/1910098?origin=crossref.

33. Nedović Ljubica, Vladan Devedžić. 2002. Expert systems in finance-a cross-section of the field.” Expert Systems with Applications 2002; 23(1): 49-66. Retrieved from: http://www.sciencedirect.com/science/article/pii/S0957417402000271.

34. Nguyen HT, Elbert W. A first course in fuzzy logic. 3rd ed. Boca Raton FL: Taylor \&amp; Francis Group, 2006.

35. Nguyen TT. Portfolio selection under higher moments using fuzzy multi-objective linear programming. Journal of 
Intelligent \&amp; Fuzzy Systems 2016; 30(4): 2139-56. Retrieved

from:http://www.scopus.com/inward/record.url?eid=2s2.084962599943\&amp;partnerID=tZOtx3y1).

36. Pedhazur EJ. Multiple Regression in Behavioral Research. 2nd ed. New York, NY: Holt, Rinehart \&amp; Winston, 1982.

37. Penman SH, Richardson SA, Irem T. The book-to-price effect in stock returns: Accounting for leverage. Journal of Accounting Research 2007; 45(2): 427-67.

38. Reilly FK, Keith B. Investment Analysis and Portfolio Management. 9th ed. Mason, OH: South-Western Cengage Learning, 2009.

39. Roll R. A critique of the asset pricing theory's tests part I: On past and potential testability of the theory. Journal of Financial Economics 1977; 4(2): 129-76.

40. Roll R, Ross SA. On the cross-sectional relation between expected returns and betas. The Journal of Finance 1994; 49(1): 101. Retrieved from: http://www.jstor.org/stable/2329137?origin=crossref.

41. Sharpe WF. Capital asset prices: A theroy of market equilibrium under conditions of risk. The Journal of Finance 1964; 19(3): 425-442.

42. Tobin J. A general equilibrium approach to monetary theory. Journal of Money, Credit and Banking 1969; 1(1): $15-29$.

43. Welch Ivo, Amit G. A comprehensive look at the empirical performance of equity premium prediction. Review of Financial Studies 2008; 21(4): 1455-1508.

44. Xidonas P, et al. On the selection of equity securities: An expert systems methodology and an application on the athens stock exchange. Expert Systems with Applications 2009; 36(9): 11966-80. Retrieved from: http://linkinghub.elsevier.com/retrieve/pii/S0957417409003170).

45. Zhou XS, Ming D. Can fuzzy logic make technical analysis 20/20?" Financial Analysts Journal 2004; 60(4): 54-75. Retrieved from: http://www.cfapubs.org/doi/full/10.2469/faj.v60.n4.2637. 